\title{
Regional and global implications for the sustainable development and education
}

\author{
Natalya Nikitina $^{1 *}$, Raisa Krayneva $^{2}$, Alexandr Platitsyn $^{3}$ \\ ${ }^{1}$ Togliatti Academy of Management, 5, Yagodinsky forestry, Stavropol district, Samara region, 445144, \\ Russian Federation \\ ${ }^{2}$ Financial University under the Government of the Russian Federation, 49, Leningradsky Prospekt, \\ Moscow, 125993, Russian Federation \\ ${ }^{3}$ Togliatti State University, 14, Belorusskaya St., Togliatti, 445667, Russian Federation
}

\begin{abstract}
Sustainable development and education are linked into a holistic and complex system that might help to transform the society by imposing the sustainable development goals and objectives. Moreover, it might contribute to the creation of the new type of global citizens who would act at regional and global levels with a focus on preserving the environment and promoting the sustainability agenda. Global civic education has been supported by the United Nations Development Programme (UNDP), the World Health Organization (WHO) and other international organizations as a means of promoting international development but the results might vary across regions and countries. We show that all of the above leads to a global approach to the development of the education system, not only for students but for society as a whole. The results of our research are likely to feed into the development of the initiatives which develop environmentally friendly attitude and promote community environmental management by creating participatory networks for the nature restoration and protection
\end{abstract}

\section{Introduction}

Sustainable development became a mantra for the $21^{\text {st }}$ century that is repeated in mass media and in the public discussions. This is not a surprise since many serious reports, studies and initiative, such as Agenda 21 or the Paris Agreement of 2015 demonstrated how alarming the situation with the global climate change might be and how hard the whole humanity needs to work together in order to prevent global environmental disasters threatening our sole existence from happening $[1,2]$.

One of the most powerful tools for promoting sustainable development is sustainable education that includes a number of tools and approaches targeted at showing the people that the environmental threats are very real but that some well-balanced and well-managed strategies and approaches might preserve the planet we live on for the future generations to come $[3,4]$.

\footnotetext{
*Corresponding author: nikitinanv_doc@mail.ru
} 
One of these approaches is the social ecology. Social ecology is considered to be a traditional ecological study in which students study how many factors need to interact with nature to create the world's ecosystems [5]. Social ecology aims to investigate how individuals interact and react with their environment and how these interactions affect society and our environment as a whole. Social ecologists examine how individuals and collective institutions interact and interact, looking at the overall picture of the system as a whole, facilitating greater communication and social cohesion, and solving society's collective problems. This facilitates the development of a more holistic view of society and its interactions with nature, which has a positive impact on the resilience of the community by enabling the collective synthesis and use of ecological knowledge. The research also shows how periods of abrupt environmental change can bring coastal communities together, creating opportunities to play a more active role in managing their natural resources [6]. This might provide new insights into the role of social ecology in various ecosystems and offer new insights that are important for the sustainability of decisions on the management of natural resources [7].

In this paper we propose to draw on the work of ecosystem scientists to develop a framework that considers environmental and sustainable education as part of an ongoing social-ecological process that includes and promotes a positive feedback loop between environmental responsibility and social-ecological processes and has regional and global implications. This view has practical implications; for example, such views may indicate that environmental and educational programs help reinforce positive feedback loops represented by existing administrations and community practices, rather than acting independently of the surrounding social and environmental systems. The perspective presented in this paper is intended to stimulate discussion on how existing approaches to environmentally friendly learning and education can be extended. We draw on the research of social-ecological systems and try to integrate environmental education into a conceptual model that describes hierarchical ecology and feedback resistance. In this paper we build on previous work on systems thinking as an integral part of ecological competence. We look at learning through the lens of interaction, participation, management and action, but in this view, we may neglect other important processes that take place within the same civic-ecological context discussed in the work. We continue to refer to socio-cultural learning theory and propose that the educational programmes in which individuals participate can be viewed from an environmental perspective.

It is apparent that much of the current thinking on sustainability can be rooted in the ability of ecological systems to explain how they can recover on different time and spatial scales in response to changes in social and environmental conditions [8]. We find that we can reconnect with past experience if we try to explain the ecology of environmental education. A number of attributes characterize systems that are able to maintain important functions in the face of human - caused or other disturbances and rebuild after a threshold of change. The first type of resilience that emphasizes adaptation and adaptability would be that of an urban community that maintains a highway built into its core. Given that many practices of civil ecology are being taken up by urban minorities and immigrants who might not otherwise be involved in the management of natural resources, they represent an opportunity to broaden the range of parties involved in environmental policy and the promotion of sustainability.

Although such practices often involve the involvement of non-governmental organizations (NGOs) and private sector stakeholders, they can also serve as a bridge organization that integrates different perspectives and knowledge into resource management. Resilience, linked to different forms of governance, such as the ability to bring different perspectives on environmental issues, helps foster change among participants in local ecosystems. For example, in some courses pupils or students might explore how to connect and interact with the managed and built environment, including public health, education, 
health care, and the environment as a whole. Students can develop their worldview by exploring concepts of diversity, social justice and consumerism in relation to the promotion and maintenance of health and well-being [9]. They might look at how connections and interactions between these systems play a key role in promoting, supporting and maintaining the well-being of individuals, communities and environments as a whole, now and in the future. Through exercise and experience, pupils and students might have the opportunity to develop links with the environment and understand the interrelations between health, human beings and the environment [10].

\section{Globalization and sustainability}

Generally, without the globalization, there would be no ties of economic exchange and political agreement that bind nations and societies, but rather a shared awareness of being part of a global system [11]. Globalisation has brought about an unstoppable change in awareness, and schools are playing an increasingly important role in this. Consciousness gives a deeper understanding of the world and a greater awareness of our place in it and our role in it. The role of education in globalisation is being put very much in the spotlight, but a multitude of other concepts are being used under the umbrella of internationalisation and globalisation with a specific focus on sustainable education [12, 13]. The different terminology refers to those who take a strong approach to internationalisation and also to those who do not. The world of globalisation is increasingly being permeated by the globalisation of education, the globalisation of technology and the internationalisation of culture and society in general.

Currently, the characteristics that lead people to believe that we are in the process of globalization, including the role of the state and the importance of nations, are not as deeply rooted as they may appear [14]. Simply put, in a world of transnational corporations and global trade, the roles of states and their importance to nations are greater. Increasingly, the world shares problems and challenges that do not obey nation states - state borders like climate change, environmental degradation, and human rights violations. The transition into the $21^{\text {st }}$ century is marked by striking differences in the expanding globalisation and globalisation of modern life and culture.

The term globalization, which is called a political - economic and socio-cultural - process, had two positive and negative effects. One consequence is a culture of emerging economies, held together by a common rhetoric focused on the "globalization of life" and "internationalization" of the world economy and society in general, as well as on international relations [15]. The level of economic globalisation has increased, which has a negative impact on the status quo in many countries and in some countries with negative effects on social and economic development. On the other hand, critics of globalisation will point out the negative impact it has on certain nations and sectors that may be exposed to increased competition from international companies. Globalization is important because it is one of the most powerful forces influencing the modern world, to the extent that it can be difficult to make sense of our world without understanding it. It can also have a positive impact on social and economic development, human rights and the environment.

Similarly, one can see that globalization has made it possible for the world's various national cultures to be diverse and inherently different. A truly multinational organization is an office or a supply chain that extends across the world. In this sense, it can be emphasized that the world is experiencing "Americanization" rather than globalization. American hegemony is reflected in the dominance of the Internet: $85 \%$ of all websites are in the United States, and American companies control more than $80 \%$ of software sales and more than $90 \%$ of the world wide web (WWW) [16]. Indeed, there seems to be a strong correlation between the rise of multinationals and the growth of globalization. It is very important that these 
powerful multinational companies also practice environmental-friendly approach and practice what is called "Corporate Social Responsibility", an approach when businesses take the responsibility for their actions related to the global climate change and attempt not only to act responsibly but also to embed the principles of the sustainable development into their corporate culture and everyday business $[17,18]$. This can be achieved through schooling, promotion, as well as educating the company's management at all levels.

\section{Global and regional dimensions of sustainable education}

The UNESCO Transition Project examines three learning dimensions that give priority to engagement with education for sustainable development (ESD) and Global Citizenship Education (GSE) learning [19]. One can examine the three dimensions of learning reflected in the GCE identified, as well as the global and regional dimensions, in order to identify the impact of these dimensions on the development of education for sustainable development. Figure 1 below shows the development of the Education Index (a part of the Human Development Index (HDI)) in the selected countries [20].

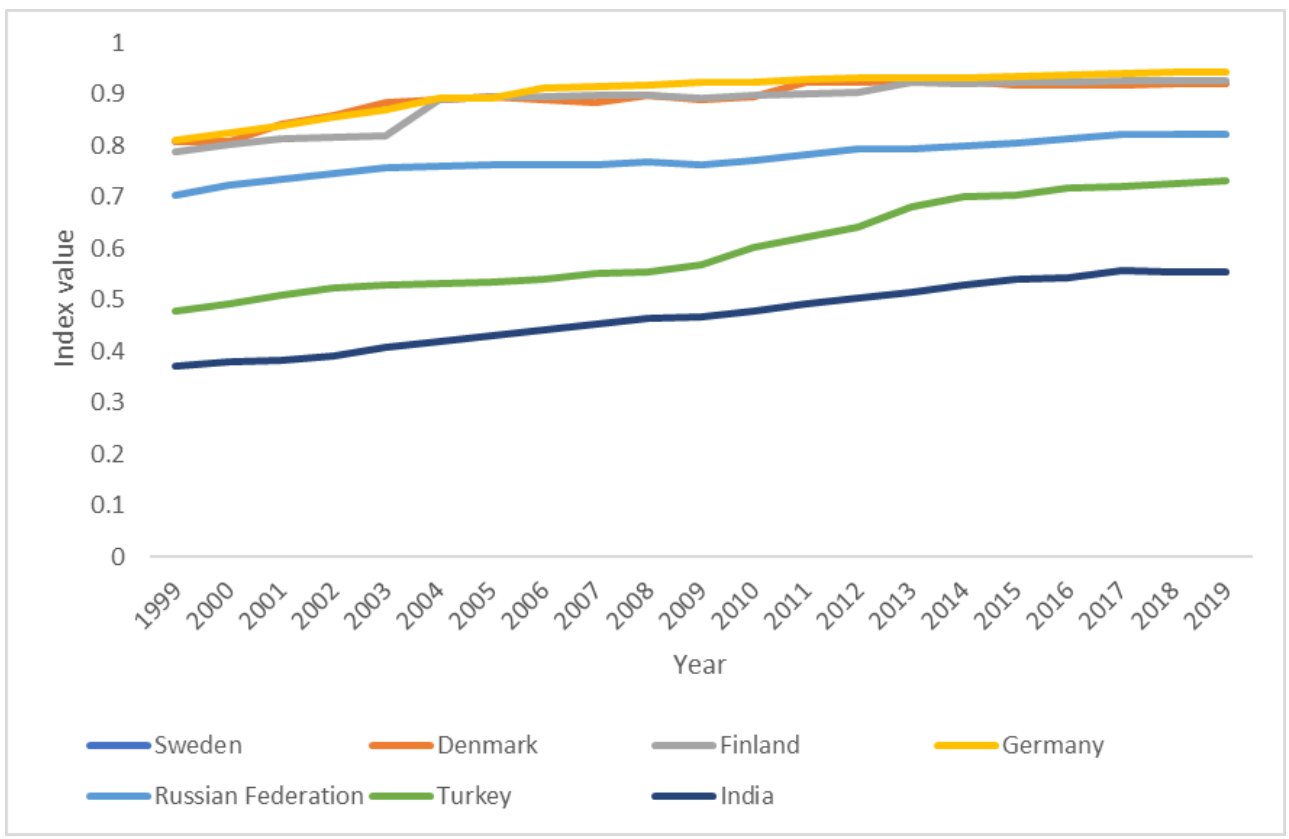

Fig. 1. Education Index in the selected countries (1990-2019)

One can see the comparison between the countries with the highest level of the total progress towards achieving all SDGs (represented here by Sweden, Denmark, or Finland) and the Russian Federation, India and Turkey. Russian Federation that ranks $57^{\text {th }}$ is closer to Sweden, Denmark and Finland that rank the first three than to Turkey $\left(70^{\text {th }}\right)$ or India $\left(117^{\text {th }}\right)$. The level of sustainable education and the attention paid to this issue at all levels of educational institutions might and also seems to correspond to this chart.

In general terms, given that many other actors are now contributing to global cooperation, the Sustainable Development Agenda cannot be driven by the international organizations alone, given the importance of the global and its role in developing education for sustainability. The integrated framework for the Sustainable Development Goals (SDG) 
presented by the United Nations requires the participation of the multitude of actors that now populate the global health landscape. Indeed, an approach to the SDGs could provide an opportunity to build a network of diverse actors by bringing together those working in the health sector. This approach can be brought together with communities, national and regional organisations to provide a framework for the development and implementation of sustainable education for sustainable health and development. Indeed, one of the most important impetus for education for sustainable development comes from the World Health Organization (WHO), and in particular from the United Nations Development Programme (UNDP). In the course of the discussion and formulation of the concept of sustainable development, it became clear that education is the key to sustainability.

In many countries, the education for sustainable development is still shaped by the educational community and the environment plays a central role, as it continues to attach great importance to participatory and inclusive education for young people, which facilitates their own decision-making. The European Commission and UNESCO attach great importance to examining how our actions at local, national and international level are connected to the world. The aim of both organisations is to raise awareness of the importance of education for sustainable development and the role of young people in the development of a sustainable future. Our work as an organisation focuses on promoting participatory and inclusive education as a key component of sustainability education. Stop Climate Chaos, a campaign by the European Commission and UNESCO that brings together local, national, regional and international organisations and individuals to fight together for the reduction of greenhouse gases. The groups involved in this campaign may come from different sectors, may have different reasons for membership, but they are working together for a common good. Climate change campaigns could serve as an opportunity for educators in the fields of environment, development and sustainable development to work towards common goals. We must promote and develop the capacity of civil society groups to work for a sustainable world.

\section{Conclusions}

All in all, it is clear that recent years are marked by the changes in society and the world economy which are likely to dramatically increase the importance of globalisation for the development of society, culture and economy as a whole. The current (and more recently) epoch of globalization is dominated by the economic, social, cultural and political developments of the $21^{\text {st }}$ century. All these developments are also subjected to the growing importance to understand the concept of globalization and to communicate it to the wider general public. We show how sustainable development began to play an important role in all spheres of human activities and how crucial it might be to provide the education for sustainable development to pupils and students at all levels of the educational process. All of these might create the solid basis for the sustainable growth and development of the society and economy including the strategies for regional development and business agenda of large and small companies.

Our results show that the key to overcoming the problem of the global warming and climate change lies in the development of citizens' initiatives in the areas of public health, education, health care and environmental protection.

Global citizenship which is emerging nowadays is an increasingly common idea: companies use the term to underscore their commitment to corporate social responsibility and sustainability around the world, universities use it to promote global awareness and international education, and there is also a movement that uses online activism and social media around the world to work toward ending global poverty. One might hear the terms' world citizenship 'and' world citizen 'in connection with the global movement for sustainable 
development and the fight against poverty and climate change. In short, it becomes clear that sustainable education is the tool that might help to promote it with a purpose to increase environmental awareness and positive attitude to the environment.

\section{References}

1. C. Hepburn, B. O’Callaghan, N. Stern, J. Stiglitz, D. Zenghelis, Oxford Review of Economic Policy, 36(1), S359-S381 (2020)

2. W. Strielkowski, E. Lisin, I. Gryshova, Romanian Journal of European Affairs, 16(4), 68-77 (2016)

3. F. Annan-Diab, C. Molinari, The International Journal of Management Education, 15(2), 73-83 (2017)

4. A. Aleixo, S. Leal, U. Azeiteiro, Journal of Cleaner Production, 172, 1664-1673 (2018)

5. D. Hummel, T. Jahn, F. Keil, S. Liehr, I. Stieß, Sustainability, 9(7), 1050 (2017)

6. G. Kennedy, M. Raimonet, M. Berman, N. Gaye, J. Huctin, T. Kaleekal, J. Vanderlinden, Global Environment, 11(2), 405-433 (2018)

7. G. Cumming, C. Allen, Ecological Applications, 27(6), 1709-1717 (2017)

8. G. Fedele, C. Donatti, C. Harvey, L. Hannah, D. Hole, Environmental Science \& Policy, 101, 116-125 (2019)

9. F. Piasentin, L. Roberts, Environmental Education Research, 24(5), 694-715 (2018)

10. J. Pretty, M. Rogerson, J. Barton, International Journal of Environmental Research and Public Health, 14(7), 706 (2017)

11. S. Babones, J. Aberg, International Theory, 11(3), 293-317 (2019)

12. I. Čábelková, V. Blaginin, W. Strielkowski, A. Platitsyn, E3S Web of Conferences, 208, 09001 (2020)

13. S. Son-Turan, International Journal of Sustainability in Higher Education, 22(1), 100119 (2020)

14. O. Petricevic, D. Teece, Journal of International Business Studies, 50(9), 1487-1512 (2019)

15. E. Makarova, E. Makarova, T. Korsakova, Journal of History Culture and Art Research, 8(1), 111-127 (2019)

16. M. Cartwright, Internet Policy Review, 9(3), 1-18 (2020)

17. A. Scherer, C. Voegtlin, Academy of Management Perspectives, 34(2), 182-208 (2020)

18. J. Lu, L. Ren, S. Yao, J. Qiao, W. Strielkowski, J. Streimikis, Energies, 12(18), 3417 (2019)

19. M. Gómez-Zermeño, Journal of Sustainable Development of Energy, Water and Environment Systems, 8(3), 577-589 (2020)

20. United Nations, Human Development Reports. http://hdr.undp.org Accessed on 15 February 2021 (2021) 